\title{
The Safety Evaluation of Salvianolic Acid B and Ginsenoside Rg1 Combination on Mice
}

\author{
Qun Zhao ${ }^{1,2}$, Min Yang ${ }^{1}$, Yanping Deng ${ }^{1}$, Haitao $\mathrm{Yu}^{1}$, Linlin Wang ${ }^{1}$, Fukang Teng ${ }^{1,2}$, \\ Kenka Cho ${ }^{3}$, Hongmei Ma ${ }^{4}$, Peng $\mathrm{Wu}^{1}{ }^{1}{ }^{2}, \mathrm{Xue} \mathrm{Li}^{1}{ }^{1}$, Wanying $\mathrm{Wu}^{1}{ }^{1}$, Xuan Liu ${ }^{1}$, Feng $\mathrm{Xu}^{2, *}$, \\ Baohong Jiang ${ }^{1, *}$ and De-An Guo ${ }^{1}$
}

Received: 30 September 2015; Accepted: 17 November 2015; Published: 9 December 2015

Academic Editor: Ge Zhang

1 Shanghai Institute of Materia Medica, Chinese Academy of Sciences, Haike Road \#501, Shanghai 201203, China; zhaoqun886@163.com (Q.Z.); m_yang@simm.ac.cn (M.Y.); shimbiro@sina.com (Y.D.); yuhaitaojerry@163.com (H.Y.); hhxxw1l@163.com (L.W.); fineskypig1983@163.com (F.T.); wp7665@sina.com (P.W.); shirley_lixue22@163.com (X.L.); wanyingwu@simm.ac.cn (W.W.); xuanliu@simm.ac.cn (X.L.); daguo@simm.ac.cn (D.-A.G.)

2 Shenyang Pharmaceutical University, Wenhua Road \#103, Shenyang 110016, China

3 Takarazuka University of Medical and Health Care, Hanayashiki-Midorigaoka, Takarazuka-City 6660162, Japan; duoli02@icloud.com

4 East China University of Science and Technology Shanghai, Meilong Road 130, Shanghai 200237, China; hmma@ecust.edu.cn

* Correspondence: xufengyaoli@sina.com (F.X.); jiangbh@simm.ac.cn (B.J.); Tel.: +86-24-2398-6265 (F.X.); +86-21-5027-2223 (B.J.)

\begin{abstract}
Our previous study indicated that the combination of salvianolic acid B (SalB) and ginsenoside Rg1 (Rg1), the main components of Salvia miltiorrhizae and Panax notoginseng, improves myocardium structure and ventricular function in rats with ischemia/reperfusion injury. The present study aimed to determine the safety of the combined SalB and Rg1 (SalB-Rg1) in mice. The safety of SalB-Rg1 was evaluated through acute toxicity and repeated-dose toxicity. In the acute toxicity study, the up and down procedure was carried out firstly, and then, the Bliss method was applied. In the toxicity study for seven-day repeated treatment of SalB-Rg1, forty Kunming mice were randomly divided into four groups. The intravenous median lethal dose $\left(\mathrm{LD}_{50}\right)$ of the SalB-Rg1 combination was $1747 \mathrm{mg} / \mathrm{kg}$ using the Bliss method. For both the acute toxicity study and the seven-day repeated toxicity study, SalB-Rg1 did not induce significant abnormality on brain, heart, kidney, liver and lung structure at any dose based on H\&E stain. There were no significant changes related to the SalB-Rg1 toxicity detected on biochemical parameters for two kinds of toxicity studies. The $\mathrm{LD}_{50}$ in mice was $1747 \mathrm{mg} / \mathrm{kg}$, which was more than one hundred times higher than the effective dose. Both studies of acute toxicity and seven-day repeated dose toxicity indicated the safety of the SalB-Rg1 combination.
\end{abstract}

Keywords: safety; salvianolic acid B; ginsenoside Rg1; acute toxicity; repeated toxicity

\section{Introduction}

The herb pair derived from the roots of Salviae miltiorrhizae (Danshen in Chinese) and Panax notoginseng (Sanqi in Chinese) has been widely used for improving coronary or cerebral circulation in China, as well as in Western countries [1,2]. Our previous study verified the significant cardio-protection for the combination of salvianolic acid B (SalB), the main active ingredient of Salviae miltiorrhizae, with ginsenoside Rg1 (Rg1), the main active ingredient of Panax notoginseng. Intravenous administration of the SalB-Rg1 combination at a ratio of 2:5 improves myocardium structure and ventricular function in rats with ischemia/reperfusion injury [3]. Either efficacy or 
safety is the precondition for new medicine development. Preliminary evaluation of toxicity becomes very necessary after elucidation of SalB-Rg1 on cardio-protection [4].

Fufang Danshen formulae, the commercially-available preparations including Salviae miltiorrhizae and Panax notoginseng, have been ranked as the first-line drugs among all Traditional Chinese Medicines in China [5]. More than 100 compounds have been isolated and identified in Salviae miltiorrhizae and Panax notoginseng to date, but only a fraction of these compounds were confirmed to be responsible for their biological effects [6,7]. Recently, an on-line coupled HPLC-DAD-ELSD method was successfully applied to the simultaneous quantification of multi-components [8]. It is unquestionable that the most abundant components among Fufang Danshen formulae are SalB, Rg1 and ginsenoside $\mathrm{Rb} 1$ (Rb1) [9].

Our study showed that the combined SalB and Rg1, rather than the combined SalB and $\mathrm{Rb} 1$, improved heart contractility in rats with myocardial infarction [10]. SalB holds antioxidant, anti-arteriosclerotic and anti-inflammatory effects and prevents angina pectoris and myocardial ischemia [11,12]. Rg1 possesses anti-fatigue properties and excites the central nervous system [13]. Our recent study elucidated that the SalB-Rg1 combination exerted better cardio-protection than mono-therapy of SalB or $\operatorname{Rg} 1$ alone, further indicating the importance to evaluate the safety of the SalB-Rg1 combination [3].

Safety assessment is a key step in drug research and development. To evaluate the preliminary safety of the SalB-Rg1 combination, an acute toxicity and a repeat-dose toxicity study on mice was conducted in the present study.

\section{Results}

\subsection{Purity of SalB and Rg1}

The purity of SalB and $\operatorname{Rg} 1$ was detected by an ultra-high performance liquid chromatography (UHPLC) system. The DAD detection wavelength was set at $280 \mathrm{~nm}$ for SalB, and an LTQ Velos Pro mass spectrometer was used as the detector for Rg1. The representative chromatogram for SalB is shown in Figure 1A, and the representative chromatogram for Rg1 is shown in Figure 1B. The purity of SalB was $98.46 \%$, and the purity of $\operatorname{Rg} 1$ was $98.35 \%$.
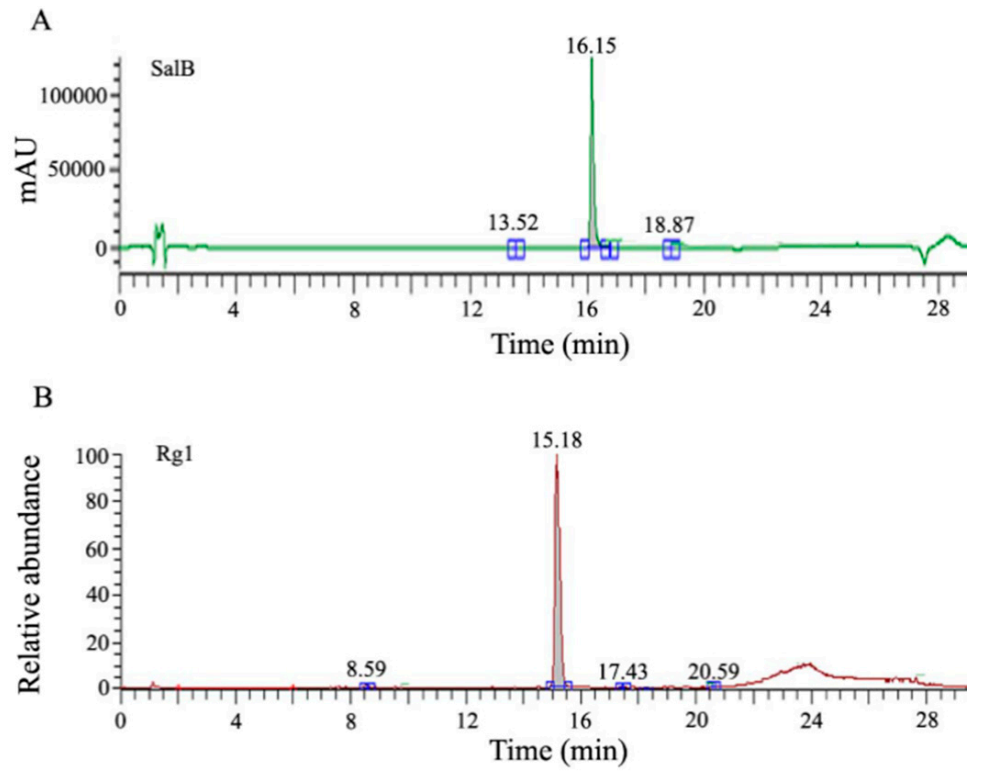

Figure 1. Representative chromatograms of salvianolic acid B (SalB) and ginsenoside $\operatorname{Rg} 1(\operatorname{Rg} 1)$.

(A) The purity of SalB was $98.46 \%$; and (B) the purity of $\operatorname{Rg} 1$ was $98.35 \%$. 


\section{2. $L D_{50}$ from the Up and Down Procedure}

In the limit test, a female mouse died after being intravenously administrated with a single dose of $2000 \mathrm{mg} / \mathrm{kg}$ SalB-Rg1. Then, the main test was performed after. In the main test, one female mouse was randomly selected and administered intravenously with a preliminary dose of $175 \mathrm{mg} / \mathrm{kg}$ SalB-Rg1. The next ascending or descending dose was determined depending on the survival from the preceding dose of the animals using a dose progression factor of 1.3. The actual dose progression is shown in Figure 2. With the dose increased to $1290 \mathrm{mg} / \mathrm{kg}$ and above, the surviving mice stayed motionless with rapid breathing, which turned back to normal within $2 \mathrm{~h}$. Almost all of the deaths occurred within 20 min after the injection. The estimated $\mathrm{LD}_{50}$ was $2560 \mathrm{mg} / \mathrm{kg}$, and the approximated $95 \%$ confidence interval was $2000-2300 \mathrm{mg} / \mathrm{kg}$, indicated by the AOT 425 Statistical Program.

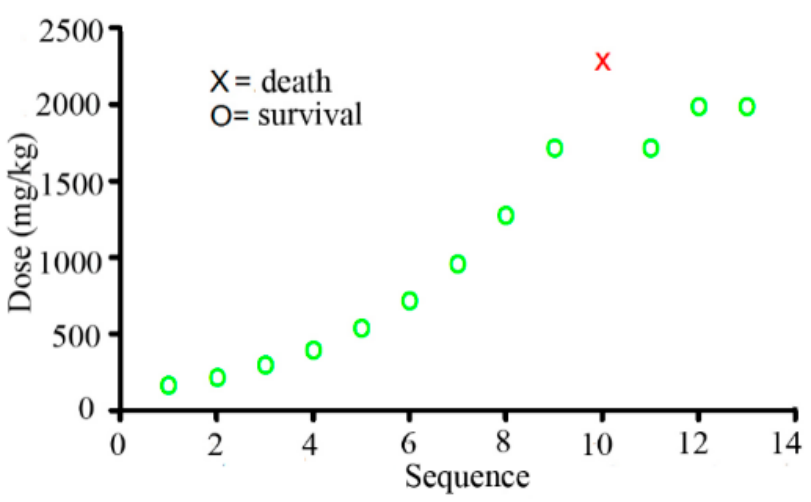

Figure 2. The sequence of the up and down procedure. The surviving animals are marked as green circles and the dead animals as a red cross. The initial dose was $175 \mathrm{mg} / \mathrm{kg}$ of the SalB-Rg1 combination.

\section{3. $L D_{50}$ from the Bliss Method with a Single Dose}

The Bliss method was employed to obtain an accurate value of $\mathrm{LD}_{50}$, and the selected dose was based on the results from the up and down procedure. Mice began to die within $24 \mathrm{~h}$ after intravenous administration of SalB-Rg1. Additionally, no more mice died during the extended observation days. The percentage of dead mice was $0 \%(0 \mathrm{mg} / \mathrm{kg}), 0 \%(1381 \mathrm{mg} / \mathrm{kg}), 20 \%(1535 \mathrm{mg} / \mathrm{kg}), 50 \%$ $(1706 \mathrm{mg} / \mathrm{kg}), 50 \%(1895 \mathrm{mg} / \mathrm{kg})$ and $90 \%(2106 \mathrm{mg} / \mathrm{kg}))$, respectively. The cumulative survival curve was drawn based on the observation covering female and male mice within $24 \mathrm{~h}$, and no more mice died thereafter (Figure 3). None of the mice died in the 1381-mg/kg treatment group. The lowest detected dose was $1535 \mathrm{mg} / \mathrm{kg}$ for mice that began to die. With the dose increased, the mortality increased (Table 1). There was no significant influence of SalB-Rg1 on body weight during the observation period in the single-dose treatment. According to the Bliss method, the calculated $\mathrm{LD}_{50}$ for SalB-Rg1 was $1747 \mathrm{mg} / \mathrm{kg}$ with a $95 \%$ confidence interval of $1640-1865 \mathrm{mg} / \mathrm{kg}$ for intravenous administration. 


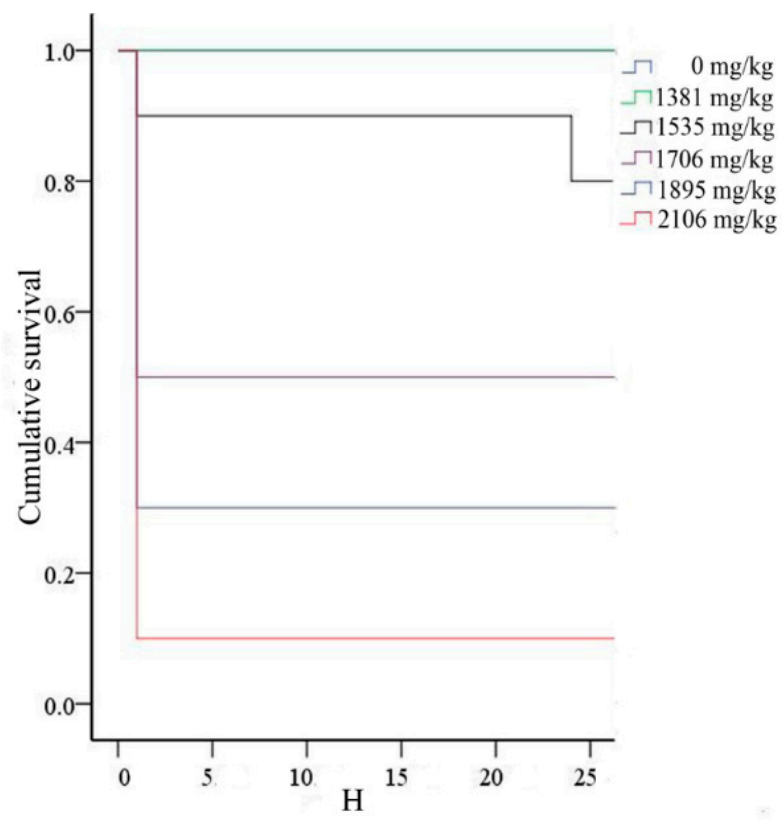

Figure 3. The survival curve for acute toxicity. All of the deaths occurred within $24 \mathrm{~h}$ after intravenous administration of SalB-Rg1.

Table 1. Effects of SalB-Rg1 on body weight and survival number with a single dose in acute toxicity.

\begin{tabular}{cccccccc}
\hline & & \multicolumn{2}{c}{ Day 0 } & \multicolumn{2}{c}{ Day 7 } & \multicolumn{2}{c}{ Day 14 } \\
\cline { 2 - 7 } & $\begin{array}{c}\text { Dose } \\
\text { (mg/kg) }\end{array}$ & $\begin{array}{c}\text { Body } \\
\text { Weight (g) }\end{array}$ & $\begin{array}{c}\text { Animal } \\
\text { Number }\end{array}$ & $\begin{array}{c}\text { Body } \\
\text { Weight (g) }\end{array}$ & $\begin{array}{c}\text { Animal } \\
\text { Number }\end{array}$ & $\begin{array}{c}\text { Body } \\
\text { Weight (g) }\end{array}$ & $\begin{array}{c}\text { Animal } \\
\text { Number }\end{array}$ \\
\hline \multirow{6}{*}{ Males } & 0 & $38.1 \pm 2.1$ & 5 & $42.2 \pm 3.3$ & 5 & $40.6 \pm 3.2$ & 5 \\
& 1381 & $37.5 \pm 1.9$ & 5 & $40.6 \pm 1.8$ & 5 & $40.4 \pm 1.9$ & 5 \\
& 1535 & $38.5 \pm 2.5$ & 5 & $42.2 \pm 3.0$ & 5 & $42.0 \pm 2.9$ & 5 \\
& 1706 & $38.0 \pm 2.5$ & 3 & $40.0 \pm 3.3$ & 3 & $39.5 \pm 2.9$ & 3 \\
& 1895 & $37.6 \pm 1.2$ & 1 & 38.7 & 1 & 35.7 & 1 \\
Females & 2106 & $38.3 \pm 2.1$ & 0 & - & - & - & - \\
& 1381 & $32.1 \pm 1.2$ & 5 & $33.8 \pm 1.7$ & 5 & $35.6 \pm 1.7$ & 5 \\
& 1535 & $31.7 \pm 2.0$ & 4 & $33.7 \pm 1.9$ & 3 & $33.4 \pm 1.7$ & 3 \\
& 1706 & $30.5 \pm 1.6$ & 2 & $35.2 \pm 0.1$ & 2 & $32.4 \pm 0.2$ & 2 \\
& 1895 & $29.9 \pm 2.4$ & 2 & $31.5 \pm 2.5$ & 2 & $32.1 \pm 2.1$ & 2 \\
\hline
\end{tabular}

Values are expressed as the mean $\pm \mathrm{SD}$.

\subsection{Effects of SalB-Rg1 on the Organ Index with a Single Dose in Acute Toxicity}

The effect of SalB-Rg1 on the organ index with a single dose is shown in Table 2. There was no significant variation on the brain, heart, kidney, liver and lung index between the control group and SalB-Rg1-treated groups for both sexes. A significant increase of the spleen index of female mice was observed in the $1535 \mathrm{mg} / \mathrm{kg}$ group compared to the control group $(4.8 \pm 0.6 \mathrm{~g} / \mathrm{kg}$ versus $3.5 \pm 0.3 \mathrm{~g} / \mathrm{kg}, p<0.01)$ and the $1895-\mathrm{mg} / \mathrm{kg}$ group compared to the control group $(5.8 \pm 0.4 \mathrm{~g} / \mathrm{kg}$ versus $3.5 \pm 0.3 \mathrm{~g} / \mathrm{kg}, p<0.01$ ). No significant difference on the spleen index was observed in male mice at any detected dose of SalB-Rg1. 
Table 2. Effects of SalB-Rg1 with a single dose on the organ index in acute toxicity.

\begin{tabular}{|c|c|c|c|c|c|c|}
\hline \multirow{2}{*}{$\begin{array}{c}\text { Organ } \\
\text { Index }(\mathrm{g} / \mathrm{kg})\end{array}$} & \multicolumn{6}{|c|}{ Dose Group (mg/kg) } \\
\hline & 0 & 1381 & 1535 & 1706 & 1895 & 2106 \\
\hline \multicolumn{7}{|l|}{ Males } \\
\hline Brain & $8.4 \pm 1.5$ & $9.2 \pm 0.8$ & $8.9 \pm 0.8$ & $8.5 \pm 0.3$ & 10.6 & - \\
\hline Heart & $5.1 \pm 0.2$ & $5.4 \pm 0.6$ & $5.6 \pm 0.7$ & $4.7 \pm 0.7$ & 4.5 & - \\
\hline Kidney & $15.4 \pm 1.3$ & $15.2 \pm 1.3$ & $15.2 \pm 0.8$ & $16.7 \pm 2.2$ & 17.9 & - \\
\hline Liver & $39.9 \pm 3.7$ & $45.1 \pm 5.4$ & $43.8 \pm 1.9$ & $40.1 \pm 0.8$ & 44.7 & - \\
\hline Lung & $7.1 \pm 0.9$ & $7.1 \pm 1.0$ & $6.8 \pm 1.5$ & $6.6 \pm 0.7$ & 7.27 & - \\
\hline Spleen & $2.4 \pm 0.4$ & $3.7 \pm 1.9$ & $2.5 \pm 0.6$ & $3.4 \pm 1.5$ & 4.5 & - \\
\hline \multicolumn{7}{|l|}{ Females } \\
\hline Brain & $9.9 \pm 1.0$ & $10.8 \pm 1.4$ & $11.7 \pm 2.6$ & $13.3 \pm 1.1$ & $11.1 \pm 2.0$ & 11 \\
\hline Heart & $4.8 \pm 0.4$ & $5.7 \pm 0.4$ & $5.8 \pm 0.5$ & $5.2 \pm 0.4$ & $3.5 \pm 0.4$ & 6.6 \\
\hline Kidney & $12.6 \pm 1.5$ & $13.0 \pm 1.4$ & $13.5 \pm 2.0$ & $13.3 \pm 0.4$ & $13.2 \pm 0.2$ & 13.4 \\
\hline Liver & $43.7 \pm 4.7$ & $46.0 \pm 3.9$ & $45.0 \pm 3.0$ & $38.5 \pm 0.17$ & $50.8 \pm 0.8$ & 43.5 \\
\hline Lung & $7.22 \pm 1.3$ & $6.9 \pm 0.7$ & $6.9 \pm 1.2$ & $6.9 \pm 0.2$ & $7.02 \pm 0.5$ & 6.4 \\
\hline Spleen & $3.5 \pm 0.3$ & $4.1 \pm 0.5$ & $4.8 \pm 0.6^{* *}$ & $2.6 \pm 0.38$ & $5.8 \pm 0.4^{* *}$ & 3.7 \\
\hline
\end{tabular}

Values are expressed as the mean $\pm \mathrm{SD}$. ${ }^{* *} p<0.01$ compared to the control group.
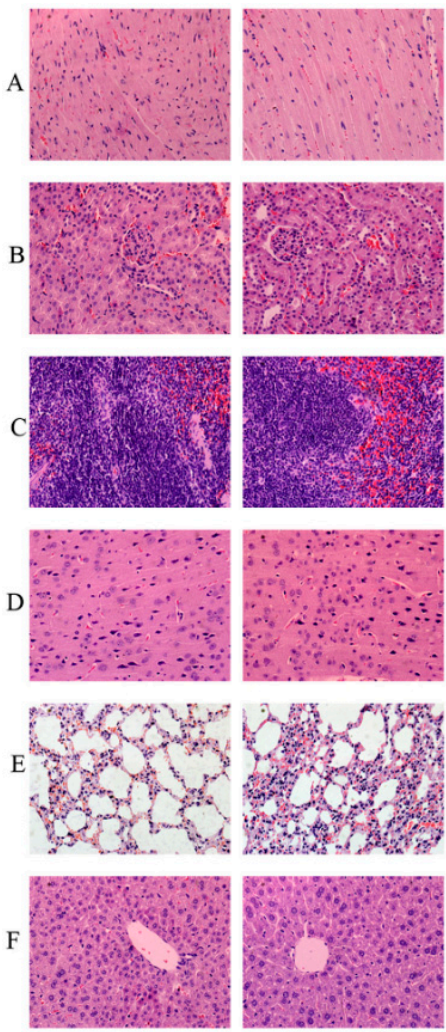

$0 \mathrm{mg} / \mathrm{kg}$
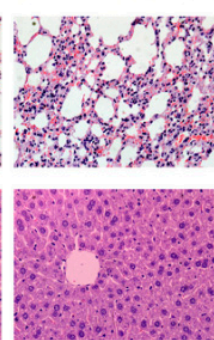

$1381 \mathrm{mg} / \mathrm{kg}$
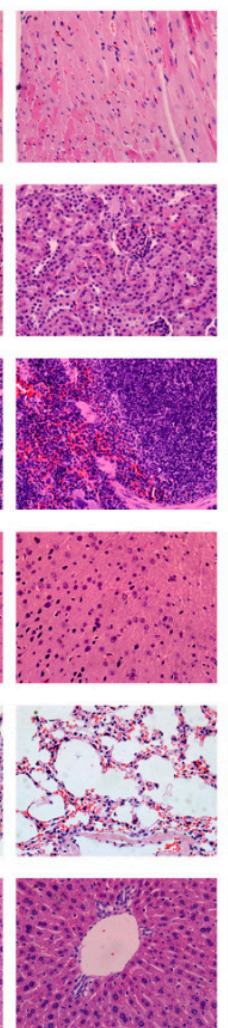

$1535 \mathrm{mg} / \mathrm{kg}$
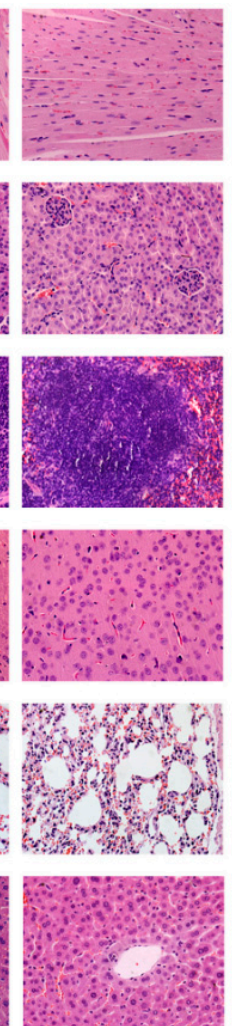

$1706 \mathrm{mg} / \mathrm{kg}$
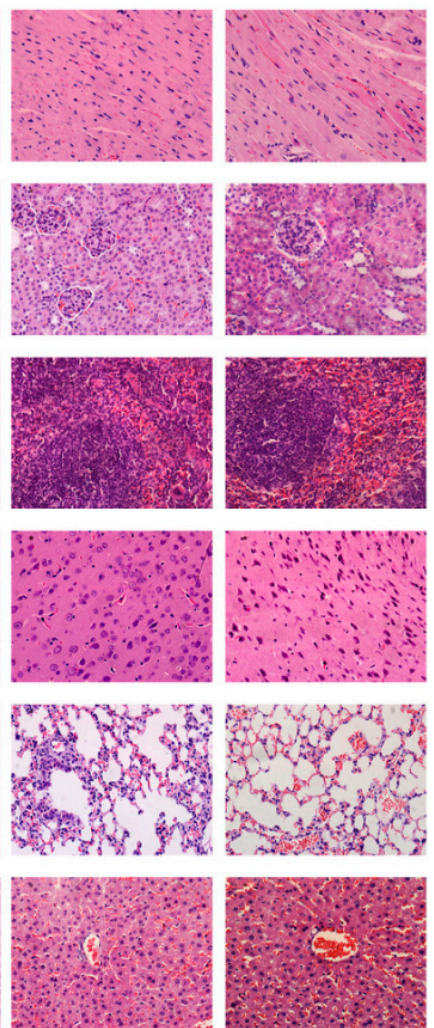

$1895 \mathrm{mg} / \mathrm{kg}$

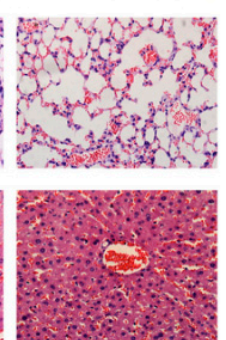

$2106 \mathrm{mg} / \mathrm{kg}$

Figure 4. Representative histological pictures of heart (A), kidney (B), spleen (C), brain (D), lung (E) and liver (F) staining with H\&E in the acute toxicity study (magnification $400 \times$ ).

\subsection{Effects of SalB-Rg1 on the Organ Structure with a Single Dose in Acute Toxicity}

The toxicity of SalB-Rg1 with a single dose was further assessed by histological examination. Representative pictures for each organ are manifested at $400 \times$ magnification in Figure 4. No abnormality was found in the endocardium, epicardium, myocardium and myocardial interstitial tissue of heart in all treated groups. As for kidney, the structure of renal cortex and medulla was 
normal, and there was no hyperemia or exudation in the renal corpuscles. Besides, there were no significant morphological alterations detected in spleen, brain and lung in all of the specimens.

\subsection{Effects of SalB-Rg1 on Biochemical Parameters with a Single Dose in Acute Toxicity}

Serum biochemical parameters were determined by commercially-available assay kits according to the instruction of the manufacture (Table 3). No treatment-related serum biochemical variation on creatinine ( $\mathrm{Cr}$ ), total protein (TP) and albumin ( $\mathrm{Alb})$ was validated in either sex of mice.

Table 3. Effects of SalB-Rg1 with a single dose on the biochemical parameters in acute toxicity.

\begin{tabular}{ccccccc}
\hline & \multicolumn{7}{c}{ Dose Group (mg/kg) } \\
\cline { 2 - 7 } & $\mathbf{0}$ & $\mathbf{1 3 8 1}$ & $\mathbf{1 5 3 5}$ & $\mathbf{1 7 0 6}$ & $\mathbf{1 8 9 5}$ & $\mathbf{2 1 0 6}$ \\
\hline Males & & & & \\
\hline $\mathrm{Cr}(\mu \mathrm{mol} / \mathrm{L})$ & $201.2 \pm 88.2$ & $159.5 \pm 38.8$ & $193.6 \pm 12.4$ & $162.3 \pm 87.2$ & - & - \\
$\mathrm{TP}(\mathrm{mg} / \mathrm{mL})$ & $48.7 \pm 2.4$ & $41.2 \pm 7.0$ & $38.5 \pm 7.5$ & $45.2 \pm 10.8$ & - & - \\
$\mathrm{Alb}(\mathrm{mg} / \mathrm{mL})$ & $19.2 \pm 2.2$ & $19.7 \pm 4.6$ & $17.3 \pm 3.7$ & $18.6 \pm 3.3$ & - & 176.5 \\
\hline Females & & & & & \\
\hline $\mathrm{Cr}(\mu \mathrm{mol} / \mathrm{L})$ & $125.3 \pm 81.3$ & $153.8 \pm 58.7$ & $100.6 \pm 71.7$ & $323.3 \pm$ & $162.3 \pm 33.6$ & 23.2 \\
$\mathrm{TP}(\mathrm{mg} / \mathrm{mL})$ & $44.0 \pm 3.7$ & $41.0 \pm 2.2$ & $47.5 \pm 6.5$ & $47.9 \pm 3.0$ & $41.7 \pm 6.2$ & 47.8 \\
$\mathrm{Alb}(\mathrm{mg} / \mathrm{mL})$ & $20.2 \pm 2.9$ & $18.0 \pm 3.8$ & $16.8 \pm 1.0$ & $19.7 \pm 0.2$ & $17.9 \pm 3.2$ & 4
\end{tabular}

Values are expressed as the mean \pm SD. Cr: creatinine; TP; total protein; Alb: albumin.

\subsection{Effects of SalB-Rg1 on Body Weight and Survival with a Seven-Day Repeated Dose for Toxicity Evaluation}

In our previous study, an effective dose for cardio-protection was used $(15 \mathrm{mg} / \mathrm{kg})$. In the present study, we evaluated the toxicity for a seven-day repeated dose of 15,30 and $60 \mathrm{mg} / \mathrm{kg}$. During the observation period of seven days, a survival rate of $100 \%$ was obtained. There was also no significant influence of SalB-Rg1 on body weight (Table 4).

Table 4. Effects of SalB-Rg1 on body weight and survival number with seven-day repeated dose toxicity.

\begin{tabular}{lccccccc}
\hline & & \multicolumn{2}{c}{ Day 0 } & \multicolumn{2}{c}{ Day 7 } & \multicolumn{2}{c}{ Day 14 } \\
\cline { 2 - 7 } & $\begin{array}{c}\text { Dose } \\
(\mathbf{m g} / \mathbf{k g})\end{array}$ & $\begin{array}{c}\text { Body } \\
\text { Weight (g) }\end{array}$ & $\begin{array}{c}\text { Animal } \\
\text { Number }\end{array}$ & $\begin{array}{c}\text { Body } \\
\text { Weight (g) }\end{array}$ & $\begin{array}{c}\text { Animal } \\
\text { Number }\end{array}$ & $\begin{array}{c}\text { Body } \\
\text { Weight (g) }\end{array}$ & $\begin{array}{c}\text { Animal } \\
\text { Number }\end{array}$ \\
\hline \multirow{4}{*}{ Males } & 0 & $23.5 \pm 1.1$ & 5 & $27.4 \pm 1.5$ & 5 & $30.8 \pm 2.2$ & 5 \\
& 15 & $23.5 \pm 1.1$ & 5 & $27.4 \pm 1.5$ & 5 & $30.8 \pm 2.2$ & 5 \\
& 30 & $22.8 \pm 0.8$ & 5 & $26.4 \pm 1.1$ & 5 & $30.0 \pm 1.5$ & 5 \\
\multirow{4}{*}{ Females } & 60 & $23.1 \pm 0.9$ & 5 & $27.0 \pm 1.3$ & 5 & $30.0 \pm 1.3$ & 5 \\
& 0 & $22.2 \pm 1.2$ & 5 & $24.7 \pm 1.3$ & 5 & $26.6 \pm 1.1$ & 5 \\
& 15 & $22.9 \pm 0.7$ & 5 & $26.9 \pm 1.0$ & 5 & $26.8 \pm 1.2$ & 5 \\
& 60 & $23.0 \pm 0.7$ & 5 & $26.6 \pm 2.2$ & 5 & $28.5 \pm 1.2$ & 5 \\
\hline
\end{tabular}

Values are expressed as the mean $\pm \mathrm{SD}$.

\subsection{Effects of SalB-Rg1 on the Organ Index with a Seven-Day Repeated Dose for Toxicity Evaluation}

The effect of SalB-Rg1 on the organ index with a seven-day repeated dose is shown in Table 5. No significant difference on the organ index, including brain, heart, kidney, spleen and lung, comparing the control group and SalB-Rg1 group with the indicated dose, was observed in either the male or female mice. 
Table 5. Effects of SalB-Rg1 on the organ index with a seven-day repeated dose.

\begin{tabular}{ccccc}
\hline \multirow{2}{*}{ Organ Index $(\mathbf{g} / \mathbf{k g})$} & \multicolumn{4}{c}{ Dose Group $(\mathbf{m g} / \mathbf{k g})$} \\
\cline { 2 - 5 } & $\mathbf{0}$ & $\mathbf{1 5}$ & $\mathbf{3 0}$ & $\mathbf{6 0}$ \\
\hline Males & $11.5 \pm 1.2$ & $11.6 \pm 1.1$ & $11.8 \pm 1.3$ & $11.7 \pm 1.1$ \\
Brain & $5.7 \pm 0.5$ & $5.2 \pm 0.3$ & $5.8 \pm 0.5$ & $5.5 \pm 0.5$ \\
Heart & $14.0 \pm 0.7$ & $13.6 \pm 0.6$ & $13.0 \pm 1.3$ & $13.6 \pm 0.9$ \\
Kidney & $7.3 \pm 0.4$ & $6.6 \pm 0.4$ & $7.0 \pm 0.5$ & $6.8 \pm 0.6$ \\
Lung & $8.3 \pm 3.4$ & $6.4 \pm 0.4$ & $6.8 \pm 0.7$ & $6.1 \pm 0.4$ \\
Spleen & & & & \\
Females & $13.4 \pm 1.7$ & $12.6 \pm 1.0$ & $12.1 \pm 1.3$ & $13.6 \pm 0.5$ \\
Brain & $5.1 \pm 0.5$ & $4.9 \pm 0.2$ & $4.9 \pm 0.5$ & $4.8 \pm 0.5$ \\
Heart & $13.3 \pm 0.6$ & $13.5 \pm 1.1$ & $13.4 \pm 0.9$ & $12.4 \pm 0.9$ \\
Kidney & $8.2 \pm 1.8$ & $7.5 \pm 0.7$ & $6.8 \pm 1.1$ & $7.4 \pm 1.2$ \\
Lung & $7.3 \pm 0.9$ & $6.5 \pm 1.0$ & $5.9 \pm 1.2$ & $6.3 \pm 1.2$ \\
\hline Spleen & &
\end{tabular}

Values are expressed as the mean \pm SD.

\subsection{Effects of SalB-Rg1 on the Organ Structure with a Seven-Day Repeated Dose for Toxicity Evaluation}

Pathological examination of SalB-Rg1 with a seven-day repeated dose study was also assessed using H\&E stain. Representative pictures for various tissue structures are manifested in Figure 5 at $400 \times$ magnification. The absence of abnormality was found on heart, liver, spleen, lung, kidney and brain with SalB-Rg1 treatment at different doses.
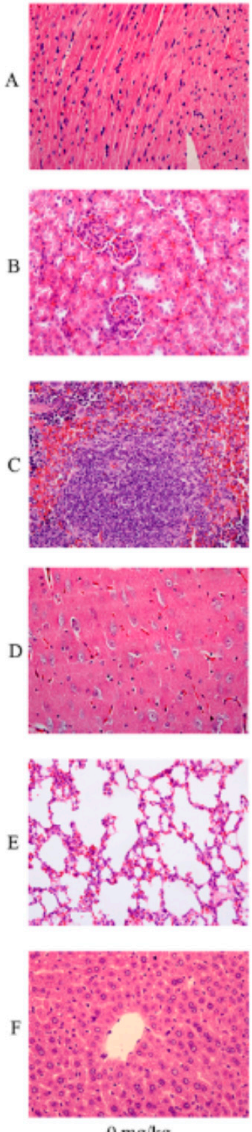

$0 \mathrm{mg} / \mathrm{kg}$
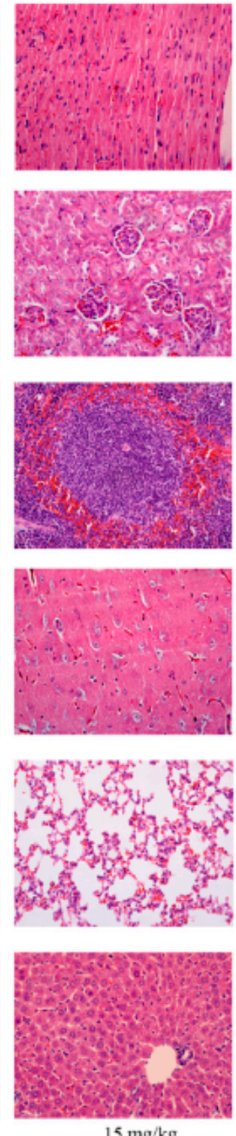

$15 \mathrm{mg} / \mathrm{kg}$
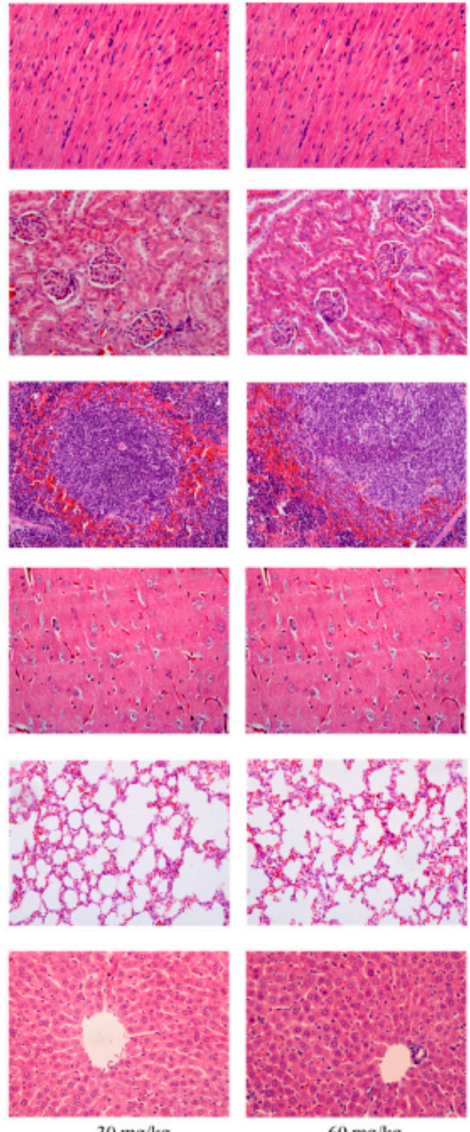

$30 \mathrm{mg} / \mathrm{kg}$

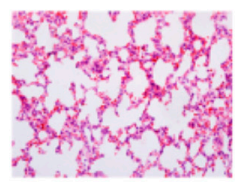

Figure 5. Representative histological pictures of heart (A), kidney (B), spleen (C), brain (D), lung (E) and liver (F) staining with H\&E in the seven-day repeated toxicity study (magnification $400 \times$ ). 


\subsection{Effects of SalB-Rg1 on Biochemical Parameters of the Seven-Day Repeated Dose for Toxicity Evaluation}

The serum concentration of biochemical parameter was also conducted to assess toxicity of SalB-Rg1 with a seven-day repeated dose (Table 6). No treatment-related serum biochemical variation on TP and Alb was found in either sex of mice. For the female mice, $60 \mathrm{mg} / \mathrm{kg}$ of SalB-Rg1 downregulated the value of Cr compared to the control group $(44.5 \pm 20.6 \mu \mathrm{mol} / \mathrm{L}$ versus $81.5 \pm 14.7 \mu \mathrm{mol} / \mathrm{L}$ ), while SalB-Rg1 did not reveal any influence on the value of $\mathrm{Cr}$ in male mice.

Table 6. Effects of SalB-Rg1 on biochemical parameters with a seven-day repeat dose.

\begin{tabular}{ccccc}
\hline & \multicolumn{4}{c}{ Dose Group (mg/kg) } \\
\cline { 2 - 5 } & $\mathbf{0}$ & $\mathbf{1 5}$ & $\mathbf{3 0}$ & $\mathbf{6 0}$ \\
\hline Males & & & \\
$\mathrm{Cr}(\mu \mathrm{mol} / \mathrm{L})$ & $76.3 \pm 49.8$ & $38.7 \pm 22.0$ & $67.1 \pm 11.3$ & $58.9 \pm 12.3$ \\
$\mathrm{TP}(\mathrm{mg} / \mathrm{mL})$ & $52.3 \pm 5.4$ & $56.1 \pm 5.4$ & $52.4 \pm 4.9$ & $52.7 \pm 5.6$ \\
$\mathrm{Alb}(\mathrm{mg} / \mathrm{mL})$ & $28.0 \pm 3.2$ & $29.6 \pm 1.7$ & $28.5 \pm 4.9$ & $28.6 \pm 3.1$ \\
\hline $\mathrm{Females}$ & & & & \\
$\mathrm{Cr}(\mu \mathrm{mol} / \mathrm{L})$ & $81.5 \pm 14.7$ & $81.5 \pm 10.6$ & $70.2 \pm 17.4$ & $44.5 \pm 20.6$ * \\
$\mathrm{TP}(\mathrm{mg} / \mathrm{mL})$ & $54.3 \pm 3.9$ & $56.4 \pm 4.9$ & $54.1 \pm 6.9$ & $53.1 \pm 4.6$ \\
$\mathrm{Alb}(\mathrm{mg} / \mathrm{mL})$ & $28.7 \pm 3.3$ & $28.7 \pm 1.8$ & $29.2 \pm 3.5$ & $33.3 \pm 3.9$ \\
\hline
\end{tabular}

Values are the mean \pm SD. Cr: creatinine, TP: total protein, Alb: albumin. Compared to the control group: $* p<0.05$.

\section{Discussion}

To evaluate the safety of the SalB-Rg1 combination, we examined acute toxicity and seven-day repeated dose toxicity in mice of both sexes. The mortality and alteration in gross observation, body weight, organ index, serum biochemistry and histopathology were monitored. The $\mathrm{LD}_{50}$ of the SalB-Rg1 combination was $1747 \mathrm{mg} / \mathrm{kg}$ for intravenous administration. No obvious toxicity was observed for both studies.

The therapeutic window is the range of drug dosages that can treat disease effectively while staying within the safety range. Medication with a narrow therapeutic window must be administered with care to avoid irreversible damage [14,15]. Even though we did not perform a rigorous study to evaluate the therapeutic window for SalB-Rg1, the obtained intravenous $\mathrm{LD}_{50}$ of SalB-Rg1 was $1747 \mathrm{mg} / \mathrm{kg}$, which was 100-times higher than the effective dose $(15 \mathrm{mg} / \mathrm{kg})$, indicating the wide safety range of SalB-Rg1.

Danshen, the dried root of Salvia miltiorrhiza, has been widely used in China, to a lesser extent in Japan, the United States and European countries, for the treatment of cardiovascular and cerebrovascular diseases [16]. Sanqi is a Chinese herbal medicine prepared from the roots of the herb Panax notoginseng [2]. The Danshen dripping pill is a popular Chinese prescription in treating coronary heart disease and angina pectoris [17]. Salvia miltiorrhiza and Panax notoginseng are the main herb composition in the Danshen dripping pill. The oral $\mathrm{LD}_{50}$ tested on the mice for a water-soluble extract of the Danshen dripping pill was $25.807 \mathrm{~g} / \mathrm{kg}$, which was equivalent to 3934-times the human oral dose $(6.56 \mathrm{mg} / \mathrm{kg})$ [18]. These results are consistent with our present findings, indicating the safety of combined Salvia miltiorrhiza and Panax notoginseng at both the extract level and the compound level.

In our acute toxicity study, mice with instant death appeared motionless, indicating the possible influence on the central nervous system. The other surviving mice returned to normal within $1 \mathrm{~h}$. It seemed that the adverse stimulation of the central nervous system was reversible. Another phenomenon was observed that the mice began to struggle when the dose increased to $1535 \mathrm{mg} / \mathrm{kg}$, while no struggling was observed on mice for the seven-day repeated toxicity, suggesting that this adverse effect was dose dependent. Commonly, abnormal alterations to body weight in toxicity studies have been regarded as critical indicators of adverse effects [19]. No significant alteration 
to body weight was found, both in the acute and repeated dose study at all doses, implying that SalB-Rg1 was well tolerated by the mice.

On the other hand, the spleen index increased in the treatment group with the doses of 1535 and $1895 \mathrm{mg} / \mathrm{kg}$ for female mice in the acute toxicity study, while a similar increase was not found in the study of seven-day repeated dose toxicity, suggesting that the influence of SalB-Rg1 on spleen was dose related. Nevertheless, the specific mechanism for the influence of SalB-Rg1 on the spleen index should be further elucidated.

In conclusion, the $\mathrm{LD}_{50}$ in mice was $1747 \mathrm{mg} / \mathrm{kg}$, which was one hundred-times higher than the effective dose $(15 \mathrm{mg} / \mathrm{kg})$. Both studies of acute toxicity and seven-day repeated dose toxicity indicated the safety of the SalB-Rg1 combination. Therefore, our results suggest that SalB-Rg1 was a safe combination for further development.

\section{Experimental Section}

\subsection{Reagents}

SalB and Rg1 were purchased from Shanghai Yousi Bio-Tech Co., Ltd (Shanghai, China). The structure of SalB or Rg1 was elucidated by the ${ }^{1} \mathrm{H}$ and ${ }^{13} \mathrm{C}$ NMR spectrum using a Bruker AM-400 spectrometer (data not shown). All of the other reagents were commercially purchased from DingGuo (Shanghai, China), unless specified otherwise. The protective effects of the SalB-Rg1 combination with various ratios were evaluated by several major hemodynamic parameters for left ventricle function, and the optimized ratio for SalB to $\operatorname{Rg} 1$ was 2:5 based on our previous data [3] (Figure $\mathrm{S} 1)$. Consequently in the present studies, the SalB-Rg1 combination at a ratio of 2:5 was employed to evaluate its toxicity.

\subsection{Animals}

This study was approved by the Animal Care and Use Committee at Shanghai Institute of Materia Medica (IACUC number: SIMM-2013-08-GDA-19), and all experiments were performed according to the Guide for the Care and Use of Laboratory Animals published by the National Institutes of Health. Healthy female and male Kunming mice were obtained from Shanghai Center of Experimental Animals, Chinese Academy of Sciences, and kept in a temperature-controlled room $\left(22 \pm 2{ }^{\circ} \mathrm{C}\right)$ with a 12 -h light and dark cycle. Water and diet were available ad libitum. The mice were acclimatized for two weeks prior to the test.

\subsection{Purity Assay for SalB and Rg1}

The purity of SalB and Rg1 was detected by an ultra-high performance liquid chromatography (UHPLC) system. Briefly, the compound solution was filtered through a $0.22-\mu \mathrm{m}$ membrane and injected into the UltiMate 3000 Binary RSLC system (Thermo Fisher Scientific Inc., Waltham, MA, USA). The column configuration consisted of a Zorbax Eclipse Plus C18 column $(1.8 \mu \mathrm{m}$, $100 \mathrm{~mm} \times 2.1 \mathrm{~mm})$ and a Zorbax Eclipse Plus C18 Guard column $(1.8 \mu \mathrm{m}, 5 \mathrm{~mm} \times 2.1 \mathrm{~mm})$. The sample injection volume was $2 \mu \mathrm{L}$. The DAD detection wavelength was set at $280 \mathrm{~nm}$ for SalB, and an LTQ Velos Pro mass spectrometer was used as the detector for Rg1; the flow rate was $0.21 \mathrm{~mL} / \mathrm{min}$, and the column temperature was maintained at $25^{\circ} \mathrm{C}$. The mobile phase consisted of (A) acetonitrile and (B) $0.1 \%$ aqueous formic acid (V/V), using a gradient elution of $10 \%-20 \% \mathrm{~A}$ at $0-6 \mathrm{~min}, 20 \%-25 \%$ A at $6-14 \mathrm{~min}, 25 \%-30 \%$ A at $14-18 \mathrm{~min}, 30 \%-90 \%$ A at $18-22 \mathrm{~min}$, then holding at $90 \%$ A for $3 \mathrm{~min}$.

\subsection{Up and Down Procedure}

Acute single-dose toxicity was assessed on the basis of mortality. Firstly, the limit test and the main test were performed following the up and down procedure of the OECD Guidelines for Testing of Chemicals No. 425 (OECD, 2006) on female Kunming mice. The state of survival and death was recorded after dosing and then kept for a further 14 days with a once daily observation for surviving 
mice. Body weight was recorded before dosing and at weekly intervals thereafter. At the end of the experiment, all surviving animals were sacrificed, and the visceral organs were examined.

For the limit test, a single limit dose of $2000 \mathrm{mg} / \mathrm{kg}$ of SalB-Rg1 was dissolved in normal saline and intravenously administered. The animal was observed, and gross necropsy was performed on the dead animal after a 2000-mg/ $\mathrm{kg}$ SalB-Rg1 administration. Because the treated animals died in the limit test, the main test was performed as follows. In the main test, one female mouse was randomly selected and administered intravenously with a preliminary dose of $175 \mathrm{mg} / \mathrm{kg}$ of SalB-Rg1. The general behavior of the animals was monitored for $24 \mathrm{~h}$ after treatment and thereafter daily up to 14 days. The next ascending or descending doses were determined depending on the survival from the preceding dose of the animals. The acute toxicity test for calculating the median lethal dose $\left(\mathrm{LD}_{50}\right)$ and the $95 \%$ confidence interval were calculated using the AOT 425 Statistical Program.

\subsection{Bliss Method}

After the up and down procedure, sixty Kunming mice were randomly divided into six groups ( $n=10$, male and female in half). Control mice received normal saline; the other five groups received graded doses (1381, 1535, 1706, 1895 and $2106 \mathrm{mg} / \mathrm{kg}$ ) of SalB-Rg1. A single dose of SalB-Rg1 was administrated intravenously at a volume of $10 \mathrm{~mL} / \mathrm{kg}$ body weight. The animals were observed for gross signs of toxicity (respiratory system, neurologic system, motor function and gastrointestinal system) and mortality for $24 \mathrm{~h}$ and then daily for a further 14 days. The $\mathrm{LD}_{50}$ was calculated following the SPSS analysis system based on the mortality throughout the study.

\subsection{Seven-Day Repeat Dose}

To evaluate the toxicity of SalB-Rg1 at the effective dose for therapy, mice were divided randomly into 4 groups ( $n=10$, male and female in half). Control mice received normal saline; the other three groups received graded doses $(15,30,60 \mathrm{mg} / \mathrm{kg})$ of SalB-Rg1 intravenously once a day for 1 week; then, mice were scarified, and the structure of the main organs (heart, liver, spleen, brain, kidney and lung) was evaluated by histopathological examination. Serum biochemical parameters were evaluated by a commercial kit according to the description of the manufacture.

\subsection{Collection of Blood and Organ Samples}

After toxic observation, the mice were anaesthetized with choral hydrate $(350 \mathrm{mg} / \mathrm{kg})$. Blood samples were collected, and serum was separated by centrifugation at $2000 \times \mathrm{g}$ for $15 \mathrm{~min}$ at $4{ }^{\circ} \mathrm{C}$, then stored at $-80^{\circ} \mathrm{C}$ until the time of the assay. Heart, liver, spleen, brain, kidney and lung were dissected out, weighed and fixed for further examination. The organ index was calculated using the equation that organ weight $(\mathrm{g})$ was divided by body weight $(\mathrm{kg})$.

\subsection{Histopathological Detection}

The main organ samples (heart, liver, spleen, brain, kidney and lung) were fixed by $4 \%$ neutral-buffered paraformaldehyde for $24 \mathrm{~h}$, and the specimens were paraffin-embedded, cut at $3 \mu \mathrm{m}$ and stained with hematoxylin and eosin. Photomicrographs were taken using an Olympus BX51 microscope plus an Olympus DP71 CCD camera (Olympus Corporation, Tokyo, Japan).

\subsection{Measurement of Biochemical Parameters on Serum}

Serum concentrations of creatinine (Cr), total protein (TP) and albumin (Alb) were determined by commercially-available assay kits (Nanjing Jiancheng Bioengineering Institute, Nanjing, China). Optical density was recorded for $\mathrm{Cr}$ at $510 \mathrm{~nm}, \mathrm{TP}$ at $540 \mathrm{~nm}$ and Alb at $510 \mathrm{~nm}$ using a microplate reader (TecanGENios, Männedorf, Austria). The concentration of each parameter was calculated according to the manufacturer's instruction. 


\subsection{Statistical Analysis}

Statistical analysis was performed by SPSS software. The $\mathrm{LD}_{50}$ from the Bliss method was calculated according to the weighted probit regression method. All quantitative values were given as the mean $\pm \mathrm{SD}$ and analyzed using one-way analysis of variance (ANOVA) following Dunnett's $t$-test. $p<0.05$ was considered to be statistically significant.

Supplementary Materials: Supplementary materials can be found at http://www.mdpi.com/1422-0067/16/ 12/26176/s1.

Acknowledgments: This work was supported by the National Science \& Technology Major Project for "Key New Drug Creation and Manufacturing Program" (2013ZX09103002-024), the National Natural Science Foundation of China Grants (81573646) and the Shanghai Science and Technology Development Foundation (14401900900). This work was also partially supported by the Croucher Foundation (CAS14201).

Author Contributions: Feng $\mathrm{Xu}$ and Baohong Jiang conceived of and designed the experiments. Qun Zhao, Min Yang, Yanping Deng, Haitao Yu, Linlin Wang, FukangTeng, Peng Wu and Xue Li performed the experiments. Kenka Cho Hongmei Ma, Wanying Wu and Xuan Liu analyzed the data. De-An Guo and Baohong Jiang wrote the paper.

Conflicts of Interest: The authors declare no conflict of interest.

\section{References}

1. Chun-Sheng, L.; Hsiao-Meng, Y.; Yun-Hsiang, H.; Chun, P.; Chi-Fen, S. Radix salviae miltiorrhizae and Rhizoma ligustici wallichii in coronary heart disease. Chin. Med. J. 1978, 4, 43-46. [PubMed]

2. Shang, Q.; Xu, H.; Liu, Z.; Chen, K.; Liu, J. Oral Panax notoginseng preparation for coronary heart disease: A systematic review of randomized controlled trials. Evid. Based Complement. Alternat. Med. 2013, 2013. [CrossRef] [PubMed]

3. Deng, Y.; Yang, M.; Xu, F.; Zhang, Q.; Zhao, Q.; Yu, H.; Li, D.; Zhang, G.; Lu, A.; Cho, K.; et al. Combined salvianolic acid $\mathrm{B}$ and ginsenoside $\mathrm{Rg} 1$ exerts cardioprotection against ischemia/reperfusion injury in rats. PLoS ONE 2015, 10, e0135435. [CrossRef] [PubMed]

4. Guengerich, F.P. Mechanisms of drug toxicity and relevance to pharmaceutical development. Drug Metab. Pharmacokinet. 2011, 26, 3-14. [CrossRef] [PubMed]

5. Yang, T.Y.; Wei, J.C.; Lee, M.Y.; Chen, C.M.; Ueng, K.C. A randomized, double-blind, placebo-controlled study to evaluate the efficacy and tolerability of Fufang Danshen (Salvia miltiorrhiza) as add-on antihypertensive therapy in Taiwanese patients with uncontrolled hypertension. Phytother. Res. 2012, 26, 291-298. [CrossRef] [PubMed]

6. Cui, H.M.; Zhang, C.G.; Lin, H.; Lu, W.L.; Cheng, H.P.; Wang, J. Determination of effective components in different positions of Panax notoginseng by HPLC. Zhong Yao Cai 2009, 32, 1810-1813. [PubMed]

7. Li, L.; Sheng, Y.; Zhang, J.; Wang, C.; Guo, D. HPLC determination of four active saponins from Panax notoginseng in rat serum and its application to pharmacokinetic studies. Biomed. Chromatogr. 2004, 18, 849-856. [CrossRef] [PubMed]

8. Wang, J.; Huang, Z.G.; Cao, H.; Wang, Y.T.; Hui, P.; Hoo, C.; Li, S.P. Screening of anti-platelet aggregation agents from Panax notoginseng using human platelet extraction and HPLC-DAD-ESI-MS/MS. J. Sep. Sci. 2008, 31, 1173-1180. [CrossRef] [PubMed]

9. Wei, Y.J.; Li, S.L.; Li, P. Simultaneous determination of seven active components of Fufang Danshen tablet by high performance liquid chromatography. Biomed. Chromatogr. 2007, 21, 1-9. [CrossRef] [PubMed]

10. Deng, Y.D.; Zhang, T.T.; Teng, F.K.; Li, D.F.; Xu, F.; Cho, K.; Xu, J.; Yin, J.; Zhang, L.; Liu, Q.; et al. Ginsenoside $\mathrm{Rg} 1$ and $\mathrm{Rb} 1$, in combination with salvianolic acid B, play different roles in myocardial infarction in rats. J. Chin. Med. Assoc. 2015, 78, 114-120. [CrossRef] [PubMed]

11. Tian, L.L.; Wang, X.J.; Sun, Y.N.; Li, C.R.; Xing, Y.L.; Zhao, H.B.; Duan, M.; Zhou, Z.; Wang, S.Q. Salvianolic acid B, an antioxidant from Salvia miltiorrhiza, prevents 6-hydroxydopamine induced apoptosis in SH-SY5Y cells. Int. J. Biochem. Cell Biol. 2008, 40, 409-422. [CrossRef] [PubMed]

12. Wang, S.X.; Hu, L.M.; Gao, X.M.; Guo, H.; Fan, G.W. Anti-inflammatory activity of salvianolic acid B in microglia contributes to its neuroprotective effect. Neurochem. Res. 2010, 35, 1029-1037. [CrossRef] [PubMed] 
13. Zhu, J.; Mu, X.; Zeng, J.; Xu, C.; Liu, J.; Zhang, M.; Li, C.; Chen, J.; Li, T.; Wang, Y. Ginsenoside Rg1 prevents cognitive impairment and hippocampus senescence in a rat model of D-galactose-induced aging. PLoS ONE 2014, 9, e101291. [CrossRef] [PubMed]

14. Kojouharov, B.M.; Brackett, C.M.; Veith, J.M.; Johnson, C.P.; Gitlin, II; Gitlin, II; Toshkov, I.A.; Gleiberman, A.S.; Gudkov, A.V.; Burdelya, L.G. Toll-like receptor-5 agonist Entolimod broadens the therapeutic window of 5-fluorouracil by reducing its toxicity to normal tissues in mice. Oncotarget 2014, 5, 802-814. [CrossRef] [PubMed]

15. Querfeld, U.; Mak, R.H. Vitamin D deficiency and toxicity in chronic kidney disease: In search of the therapeutic window. Pediatr. Nephrol. 2010, 25, 2413-2430. [CrossRef] [PubMed]

16. Shi, M.; Luo, X.; Ju, G.; Yu, X.; Hao, X.; Huang, Q.; Xiao, J.; Cui, L.; Kai, G. Increased accumulation of the cardio-cerebrovascular disease treatment drug tanshinone in Salvia miltiorrhiza hairy roots by the enzymes 3-hydroxy-3-methylglutaryl CoA reductase and 1-deoxy-D-xylulose 5-phosphate reductoisomerase. Funct. Integr. Genom. 2014, 14, 603-615. [CrossRef] [PubMed]

17. Jia, Y.; Huang, F.; Zhang, S.; Leung, S.W. Is danshen (Salvia miltiorrhiza) dripping pill more effective than isosorbide dinitrate in treating angina pectoris? A systematic review of randomized controlled trials. Int. J. Cardiol. 2012, 157, 330-340. [CrossRef] [PubMed]

18. Zhou, L.; Zuo, Z.; Chow, M.S. Danshen: An overview of its chemistry, pharmacology, pharmacokinetics, and clinical use. J. Clin. Pharmacol. 2005, 45, 1345-1359. [CrossRef] [PubMed]

19. Flood, M.T.; Kondo, M. Safety evaluation of lipase produced from Candida rugosa: Summary of toxicological data. Regul. Toxicol. Pharmacol. 2001, 33, 157-164. [CrossRef] [PubMed]

(C) 2015 by the authors; licensee MDPI, Basel, Switzerland. This article is an open access article distributed under the terms and conditions of the Creative Commons by Attribution (CC-BY) license (http:/ / creativecommons.org/licenses/by/4.0/). 